\title{
An activity-based modelling framework for quantifying occupants' energy consumption in residential buildings
}

\author{
Yann Leroy ${ }^{1}$, Bernard Yannou ${ }^{1}$ \\ Laboratoire Genie Industriel, CentraleSupélec, Université Paris-Saclay, 91190 Gif-sur-Yvette, \\ France \\ ${ }^{1}$ Corresponding author:
}

Yann Leroy

Laboratoire Genie Industriel, CentraleSupélec, Université Paris-Saclay, 91190 Gif-sur-Yvette, France

Email : yann.leroy@centralesupelec.fr

Phone: +33175316802

\begin{abstract}
The residential building is a major energy consumer and pollution source worldwide. The shift towards constructing energy-efficient buildings is impelling higher performance. In sustainable building, occupants become a major source of uncertainty in energy consumption. Yet, energy simulation tools often account for occupant behaviour through predefined fixed consumption profiles. Therefore, energy and buildings experts are in need for more precise methods for better forecasting the influence of occupants on the building performance. An activity-based framework for quantifying occupant-related energy consumption is proposed. The energy consumption is quantified per domestic activity as a function of households' socio-demographic and economic attributes. The aggregation of such domestic activity energy consumption provides an accurate estimation of the household energy consumption per daily, monthly and annually periods. First, a literature review about residential energy consumption and the existing modelling approaches is presented. Second, a systematic breakdown structure of energy end-uses is proposed. The activity-based framework is then introduced. An application example is demonstrated together with simulation results. Finally, model's utility is outlined and its possible implications are discussed.
\end{abstract}

Key words: Energy modelling framework, simulation model, residential building, occupant behaviour, household profile, domestic activity. 


\section{Introduction}

The building sector is a substantial energy consumer and environment pollutant in most countries. It accounts for important shares, ranging between 16 and 50 percent, of national energy consumptions worldwide [1-4]. In order to reduce these consumptions and emissions and to promote sustainable development, authorities around the globe are thus establishing energy directives and regulations that help optimising building's performance. Examples of these directives are the European "Energy Performance of Buildings" (or EPBD) and the latest French thermal regulation RT2012 [5]. Moreover, various energy efficiency labels and green building rating systems already exist worldwide, such as BREEAM in the U.K, LEED in the United States, and BBC-Effinergie in France [6]. Such energy labels and certifications encourage the use of best practices and the development of energy efficiency solutions that go beyond the minimum requirements stipulated by standards and regulations. As a result of such norms and labels, building actors are tending progressively to construct energy-efficient and green buildings. This is also accompanied with new market expectations such as the "energy performance contracts" that impel constructors to deliver energy-efficient buildings and to guarantee their performance level for a number of years [7]. As a result, a better comprehension and integration of building performance determinants into the design of buildings has become essential. At the same time and due to the deployment of smart meter, providing a solution for visualizing real time energy consumption is now a legal requirement. A better comprehension of such occupants' behaviours is a promising way to engage occupants towards a reduction of their energy consumptions by the mean of nudges dissemination.

The energy performance of a building is governed by various parameters, such as its physical characteristics, its external environment, its internal services systems and equipments, and most importantly the behaviour of its occupants [8-10]. Industrial energy simulation tools, such as Energy Plus, eQUEST, ESP-r and TRNSYS, focus primarily on the structural behaviour of buildings and their relations to specific environmental conditions while taking insufficiently the role of the occupants into account [11,12]. This simplification of occupants' behaviour may leads to unrealistic energy estimates $[11,13]$. Therefore, energy and buildings experts are in need for tools that enable them to model more accurately the influence of occupants on the whole-building performance. Such models can thereby be used as complementary tools for existing industrial ones in order to provide more accurate estimates of residential energy consumption and accompany inhabitants towards the reduction of the energy consumption. Consequently, some design and technical solutions may be better adapted and energy performance contracts (guarantees) may be better adjusted.

\section{Literature review}

\subsection{Occupants and residential energy consumption}

The residential sector consumes secondary energy, i.e. electricity and hydrogen produced from primary energy sources such as coal, natural gas, petroleum, nuclear energy and renewable energy sources, which is used by occupants for performing their domestic activities. Several studies pointed out the major end-use groups of secondary energy such as space heating, space cooling, domestic hot water, as well as appliances and lighting [14-17]. Building's energy consumption is highly dependent on the performance of its systems and the general behaviour of the occupants [18]. According to Robinson [19], the most complex processes taking place within buildings are those that result from human behaviour. Authors such as Emery and Kippenhan [20], Masoso and Grobler (2010), and Guerra-Santin and Itard [21] also reveal occupants' influence on residential energy consumption. Authors such as Page et al. [22], Robinson [19] and Wilke et al. [18] show that the influence of occupants can be modelled by their presence, the actions they perform (activities such as cooking, using light, etc.), as well as their interactions with the controls of inherent building systems designed for adjusting the indoor environment (e.g., lighting and HVAC). 
Occupant behaviour is considered as a substantial source of uncertainty in energy modelling since energy use can vary dramatically between different households [23-26]. Swan and Ugursal [15] reveal that occupant behaviour in residential buildings varies widely and can impact energy consumption by as much as $100 \%$ for a given dwelling. This variation is mainly due to the variability in occupant profiles. Literature confirms the high correlations between household attributes on the one hand, and domestic appliances ownership levels, their energy rating, and their use patterns on the other [27-29]. For instance, Yun et al. [30] affirm that household income is an important factor in determining ownership of air conditioning equipments. Barr et al. [31] explain that the environmental concern is the major determinant for the purchase of energy-saving appliances such as washing machines, cookers, and dishwashers. Pachauri [9] concludes that the total household income level may cause high variations in energy requirements across Indian households. Lutzenhiser et al. [32] confirm that household attributes such as income, education, family size, occupation hours, and household are highly influential on energy consumption. Guerin et al. [33] identify household income, age, education level, home ownership, desire for comfort, and energy conservation incentives as influencing factors. Similar variables are also reported by Nugroho et al. [34] and Santamouris et al. [35]. McLoughlin et al. [36] identify the number of occupants, disposable income, head-of-household age, tenure type, social group, education level, and appliance ownership as the most influencing factors on residential energy consumption. To summarize, considering the energy consumption of household in green or passive building is highly dependent occupants' behaviors, appliances and devices and the way they interact each other, all the aforementioned factors are directly or indirectly (income, education, etc...) occupant driven.

\subsection{Modelling energy consumption in residential buildings}

A number of techniques and approaches have been developed to model energy consumption in residential buildings. According to Swan and Ugursal [15], these approaches are either top-down (econometric or technological) or bottom-up (statistical or engineering) approaches, where each of them comprise a number of scientific techniques [15,36]. To model occupant-related residential energy consumption, some researchers use sub-metering on measured data in order to derive representational loads of households' energy use, and thus deduce estimates of buildings' energy consumption. Authors such as Seryak \& Kissock [24], Yohanis et al. [37] adopted such an approach. Although such frameworks can generate representative load profiles and provide some insights about occupants' role in energy consumption, they do not depict occupants' behaviour and preferences towards energy consumption. Another widespread modelling approach is uses of stochastic techniques for simulating occupancy patterns and various energy-load schedules. This second approach uses other source of information, namely the time use surveys (TUS), instead of using sub-metering data, The TUS are large-scale time-use surveys conducted at the national level, where each TUS record contains information on 24-hour period of activities of a given individual [38]. Then by applying stochastic techniques such as Monte Carlo Markov Chains (MCMC), daily activity patterns of energy consumption may be derived. Shimoda [39] uses data from 2000 Japanese Time-Use Survey (JTUS) to create typical occupant schedules for residential end-use energy simulations of Osaka City. Tanimoto [40] proposes a stochastic approach for residential cooling-load calculations. The same author develops later a method to simulate the load schedules for appliances, lighting, and hot water [41]. Richardson et al. [42] introduce a Markov-chain technique to generate synthetic active occupancy patterns, based upon time-use surveys in the United Kingdom. The stochastic model proposed by these authors provides a mapping between occupants' activities (state) on the one hand and appliance use on the other, creating thus highly resolved synthetic energy demand data. In their results, Richardson et al. [42] find good match between occupancy profiles yielded by the model and real profiles taken from the TUS data. Based on this occupancy model, the same authors developed a lighting model and a domestic electricity demand model [43,44]. Widén and Wäckelgård [45] develop a high-resolution stochastic model of domestic activity patterns and electricity demand in Sweden. They identify nine different electricity-dependent activities such as sleeping, cooking, dishwashing, cloth washing, TV and others. The authors associate each of these activities to its corresponding domestic appliance(s). By defining load patterns for each appliance, they are 
capable to estimate the total electricity demand per household. The authors show that realistic demand patterns can be generated from these activity sequences. Muratori [46] and Wilke et al. [18] use heterogeneous Markov chains to model domestic activity patterns of individuals and to predict energy consumption of households. Subbiah [47] uses American TUS data for developing a disaggregated energy demand-modelling framework that estimates energy demand profiles based on individual-level and building-level energy-consuming activities. Subbiah [47] claims that his model can result in better results than other TUS-based models since it can account for interactions between household members and that it computes domestic activities at both individual and household levels.

Other approaches stemming from artificial intelligence domain have started to be applied for modelling the dynamic aspects of energy consumption in buildings. Kashif et al. [13] propose a conceptual framework to simulate dynamic group behaviour by using an agent-based approach. The authors use this framework to predict the energy consumption of a household by simulating the interactions between inhabitants living in the same home. Quijano et al. [48] propose an agent-based simulation platform called SMACH (for multiagent simulation of human behaviour) for assessing the impact of the adaptive behaviour of various electrical appliances on the overall consumption of dwellings. The human agents imitating individuals' behaviours are modelled from observations in the real world of some volunteer families. As concluded by Quijano et al.[48], the major limitation of their approach is that the different strategies have not been tested in a real environment and that it would be difficult to identify the activity of each individual at every moment.

\subsection{Research gaps with regard to occupant-related energy consumption frameworks}

Based on this literature review, a number of shortcomings of the existing models may be revealed. First, models in literature do not account sufficiently to household variables while quantifying residential energy consumption [49]. In most of the approaches, the only variable considered for representing households' attributes is the number of occupants (e.g. Richardson et al. [43], Widén \& Wäckelgård [45]). This means that such models cannot assess the variability of energy consumption between two households having the same number of occupants but of different income level. Secondly, there has been little published work for generating energy demand profiles with a very fine granularity, meaning at the level of individuals, which is an important aspect for depicting sharing phenomena of appliances and activities. For instance, if two or more individuals are watching TV at the same time, the energy consumption of the appliance must be counted only once. Thirdly, to the authors' knowledge, none of the existing frameworks presents a modeldriven approach for quantifying energy consumption of domestic activities. Most of the published models are based either on monitored consumption data or on time use surveys, and therefore on correlations between occupancy patterns on one hand and appliance use on another. Therefore, as no explicit correlation between socio-demographic attributes and energy consumption (occupancy patterns and appliance ownership and uses), a reliable quantification of domestic activities and their yielded consumption as a function of occupants' socio-demographic and economic attributes cannot be established through such approaches.

\subsection{Proposed modelling framework}

In this paper, we have demonstrated a bottom-up activity-based parametric modelling framework which is capable of forecasting energy consumption spectrums of a household as a function of its socio-demographic and economic attributes. A main novelty of the proposed framework is its capability to quantify energy consumption per domestic activity at a very fine granularity (domestic activity), at the level of a specific individual occupant and/or household. The modelling framework can thus be used to assess the variability in consumption values provided the diversity of households' characteristics in order to refine household profiles in thermal simulations and energy consumption visualization data.

In this paper, a systematic breakdown structure of energy end uses in residential buildings is first established in section 3. An activity-based framework for modelling households' energy consumption is then proposed 
in section 4. In the same section, an exhaustive inventory of energy-consuming activities is established, model's ontology is introduced, and energy quantification mechanisms are presented. A direct application of the framework for one domestic activity is then proposed in section 5. The modelling procedure is presented and a sample of simulation results is given. Finally, framework's features and its utility are discussed in section 6 .

\section{Energy consumption breakdown in residential building - Scope of the research}

According to literature review, energy use of residential buildings may be divided into two categories of sources. The first category encompasses the energy used by indoor environmental-control devices and systems such as lighting, heating, ventilation and air conditioning (HVAC) that occupants use for adjusting their comfort levels. These devices and systems belong to the dwelling and are controlled by end-users. The second category however includes the appliances that occupants use for performing their daily living activities such as cooking, washing, and entertainment.

In order to better represent these energy uses, we propose here a breakdown structure which segregates residential energy consumption at three levels. The proposed breakdown structure is illustrated in Figure 1.

\section{Building}

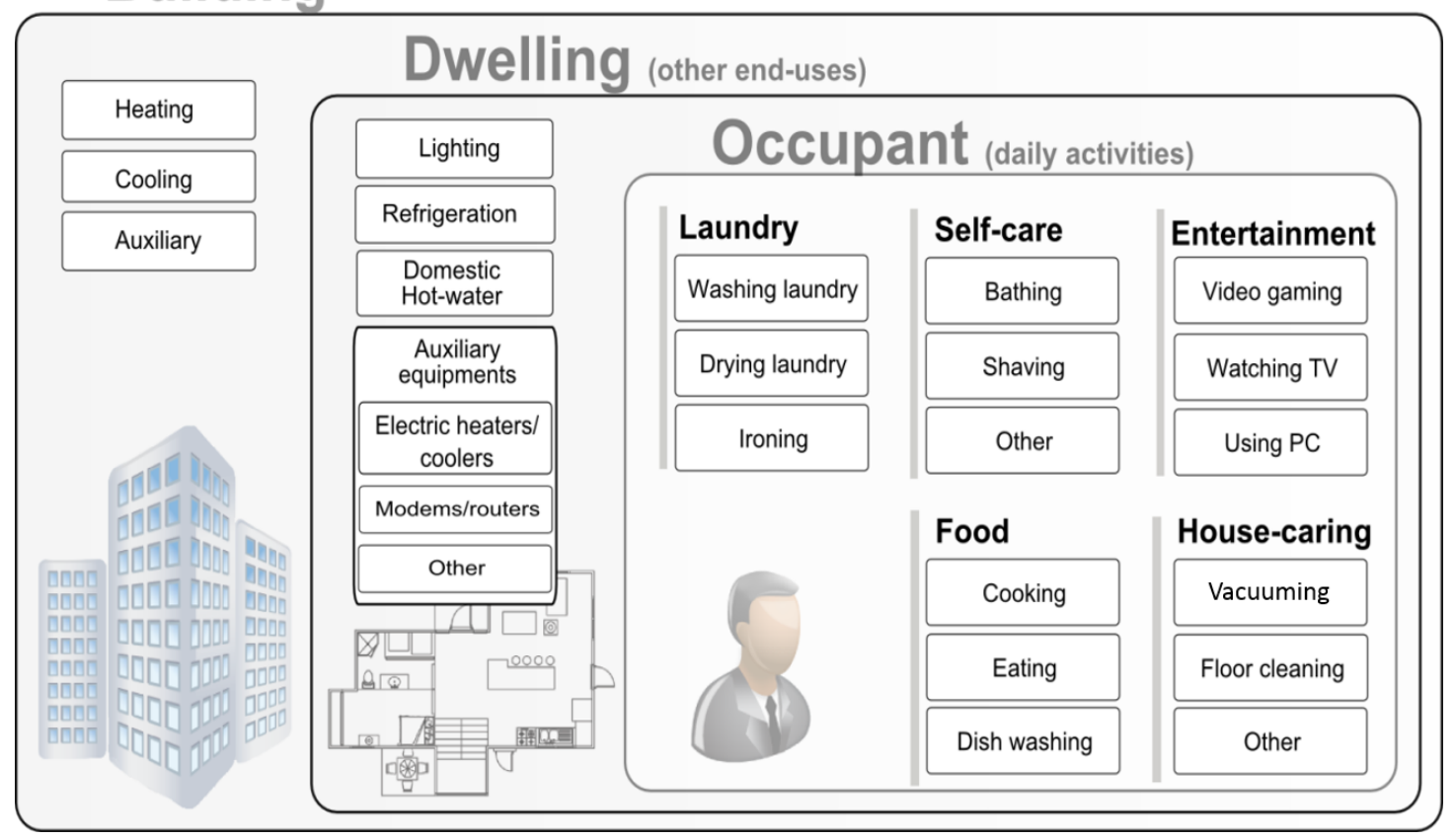

Figure 1: Systematic breakdown structure of energy consumption in residential building

The first level is the building level, which comprises the end-uses of inherent systems and equipments installed for the general services of the building. These end-uses are: heating, cooling, ventilation, lighting (in building's common areas in case of multi units building), and centralized domestic hot water in some cases. The influencing factors of energy consumption at this level are mainly attributed to building's physical characteristics (altitude, orientation, insulation, wall type, etc.) and to the external climate (temperature, humidity, wind, etc.).

The second and third levels of the structures represent the energy consumption due to occupants' activities and their domestic appliances. The second level, corresponding to the dwelling level, comprises common 
domestic energy usages of occupants such as: lighting (inside dwelling), cold (refrigerators and freezers), personal heating and cooling (electrical), and other auxiliary equipments (e.g. internet boxes, routers, etc.). The consumption pattern of these end-uses is said to be transversal or diffuse. Some of them consume energy continuously (such as refrigerators) and others non-continuously (such as lights). Their use by household members is not associated to a major activity itself, but it is rather for getting a necessary comfort (e.g. visual) for accomplishing a set of domestic activities (e.g. using light for reading or for eating).

At the third level, we position the energy consumptions due to major intentional domestic individual activities such as watching TV, washing dishes, and doing laundry. As shown in literature, energy use at this level is mainly influenced by occupants' socio-demographic attributes and their lifestyle. An exhaustive list of these activities is established and presented in Table 1. Some activities may be grouped in so-called 'aggregated activities' which are defined according to the daily life needs of household members. For example, the aggregated activity "Laundry" comprises three elementary domestic activities: washing laundry, drying laundry, and ironing laundry. These activities are characterized by their specific nature (shared or additive) and an activity Service Unit that allows to quantify the amount of activity that is performed. These two characteristics are defined and discussed in depth in section 4.4 and 4.5.

As confirmed in literature, the energy consumption of end-uses such as heating, cooling, lighting, ventilation depends highly on the structural characteristics of the building. Nowadays, a good understanding of these end-uses has been established, and international regulations and documentations are settled. Their yielding energy consumption is thus modelled and simulated within energy simulation tools with a good precision. On the other side, energy consumption of domestic activities such as cooking, multimedia, informatics and others is still less explored [45]. In fact, energy consumption at the third level (occupant level) represents a major part of energy use especially in the case of green buildings and passive buildings for which systems at the building dwelling levels are optimized and become more robust and resilient. In addition, a main feature of these end-uses is their variability among different households due to their high dependency on occupant's socio-economic and demographic characteristics [50]. Given these facts, the research work of the present paper is focused on modelling occupant-related energy consumption due to domestic activities (second and third levels). The energy use at the first level (building level) is excluded from considerations.

Table 1: Detailed list of activities, needs and actions

\begin{tabular}{|c|c|c|c|}
\hline Need category & Activity & Activity's service unit (SU) & Activity nature \\
\hline \multirow{5}{*}{ House-caring } & Dish washing & Total quantity of used dishes and cutlery/ week & Shared and/or additive \\
\hline & House cleaning & Total surface to be cleaned (m2)/ week & Additive \\
\hline & Washing laundry & $\begin{array}{l}\text { Total quantity of } \\
\text { used laundry }(\mathrm{kg}) / \text { month }\end{array}$ & Additive \\
\hline & Drying laundry & $\begin{array}{l}\text { Total quantity of } \\
\text { used laundry }(\mathrm{kg}) / \text { month }\end{array}$ & Additive \\
\hline & Ironing laundry & Quantity of laundry to be ironed $(\mathrm{kg}) / \mathrm{month}$ & Additive \\
\hline \multirow{9}{*}{$\begin{array}{c}\text { E.I.C. } \\
\text { (Entertainment, } \\
\text { Information and } \\
\text { Communication) }\end{array}$} & Watching TV channels & $\begin{array}{l}\text { Total duration of watching TV channels } \\
(\mathrm{min}) / \text { week }\end{array}$ & Shared and/or additive \\
\hline & Watching videos & Total duration of watching videos (min)/week & Shared and/or additive \\
\hline & Playing video games & $\begin{array}{l}\text { Total duration of playing video games } \\
\text { (min)/week }\end{array}$ & Shared and/or additive \\
\hline & Listening to music and radio & $\begin{array}{l}\text { Total duration of listening to music } \\
\text { and radio (min)/week }\end{array}$ & Shared and/or additive \\
\hline & Playing music & Duration of playing music (min)/week & Additive \\
\hline & Surfing on the internet & $\begin{array}{l}\text { Total duration of surfing on the internet } \\
(\mathrm{min}) / \text { week }\end{array}$ & Additive \\
\hline & Reading & Total duration of reading $(\mathrm{min}) /$ week & Additive \\
\hline & Communicating & Total duration of communicating $(\mathrm{min}) /$ week & Additive \\
\hline & Printing and scanning & Number of printed and scanned pages/week & Additive \\
\hline If-feeding & Eating & Total number of taken foods/ week & Shared and/or additive \\
\hline
\end{tabular}




\begin{tabular}{|c|c|c|c|}
\hline & Food conserving & $\begin{array}{l}\text { Total quantity of food conserved in refrigerator } \\
\text { and/or freezer }(\mathrm{kg}) / \text { week }\end{array}$ & Additive \\
\hline & Food preparing & Quantity of washed aliments $(\mathrm{kg}) /$ week & Additive \\
\hline \multirow{6}{*}{ Self-care } & Hand washing & Number of washed pairs of hands/ week & Additive \\
\hline & Bathing & Total number of baths and showers taken/ week & Additive \\
\hline & Tooth brushing & Total number of tooth brushing/ week & Additive \\
\hline & Shaving & Total number of shaving/ week & Additive \\
\hline & Hair dressing & Total number of hair dressing/ week & Additive \\
\hline & Go to toilet & Total number of "going to toilet"/ week & Additive \\
\hline \multirow{2}{*}{ Thermal Comfort } & Heating & Heating duration $(\mathrm{min}) /$ week & Shared and/or additive \\
\hline & Cooling & Cooling duration (min)/ week & Shared and/or additive \\
\hline \multirow{3}{*}{$\begin{array}{c}\text { Indoor Air } \\
\text { Quality Comfort }\end{array}$} & Ventilating & Ventilating duration $(\mathrm{min}) /$ week & Shared and/or additive \\
\hline & Air extracting & Air extracting duration (min)/ week & Shared and/or additive \\
\hline & Air purifying and humidifier & $\begin{array}{l}\text { Air purifying and humidifying duration (min)/ } \\
\text { week }\end{array}$ & Shared and/or additive \\
\hline Visual Comfort & Use lighting & Lighting duration $(\mathrm{min}) /$ week & Shared and/or additive \\
\hline
\end{tabular}

\section{An activity-based energy consumption modelling framework of occupant- related energy consumption}

An activity-based approach is proposed here for modelling occupants' energy consumption yielded by domestic activities. Activity-based approach entails that energy consumption of a household is estimated through summing up the energy use due to different activities carried out. The proposed framework lies on two major hypothesis. First, activities in a dwelling must be enounced in such a way that they do not overlap on each other and the cumulative sum of energy consumed per each activity may be used to globally assess energy consumption of a household in a dwelling. Second, an activity quantity per household is estimated based on the activity quantities per individuals. For this point, cumulative summation may be assumed for a given activity but of course the sharing of activity or economies of scale may diminish this basic summation (e.g. for the watching TV activity). The structure of the proposed Activity-Based Energy Consumption modelling framework is presented as a UML class diagram in Figure 2, where its different objects are explained in the following section. The numbers on the edges represent cardinalities between model objects. For instance, the notation $\left(1 . *^{*}\right)$ indicates that an activity may have one or more corresponding actions.

\subsection{Characterizing occupant behaviour with regard to energy consumption}

Occupants perform domestic activities to satisfy their needs and well-being, such as house carrying, preserving and preparing food, supplying heat and light and maintaining health and sanitation [26]. Most of these activities require the usage of certain appliances that consume energy (electricity, gas, fuel) and water. We characterize occupants' behaviour towards energy and water consumption through a need-activityaction paradigm. The latter is inspired from the activity theory (from social sciences), which states that the human behaviour can be represented through activities [51]. 


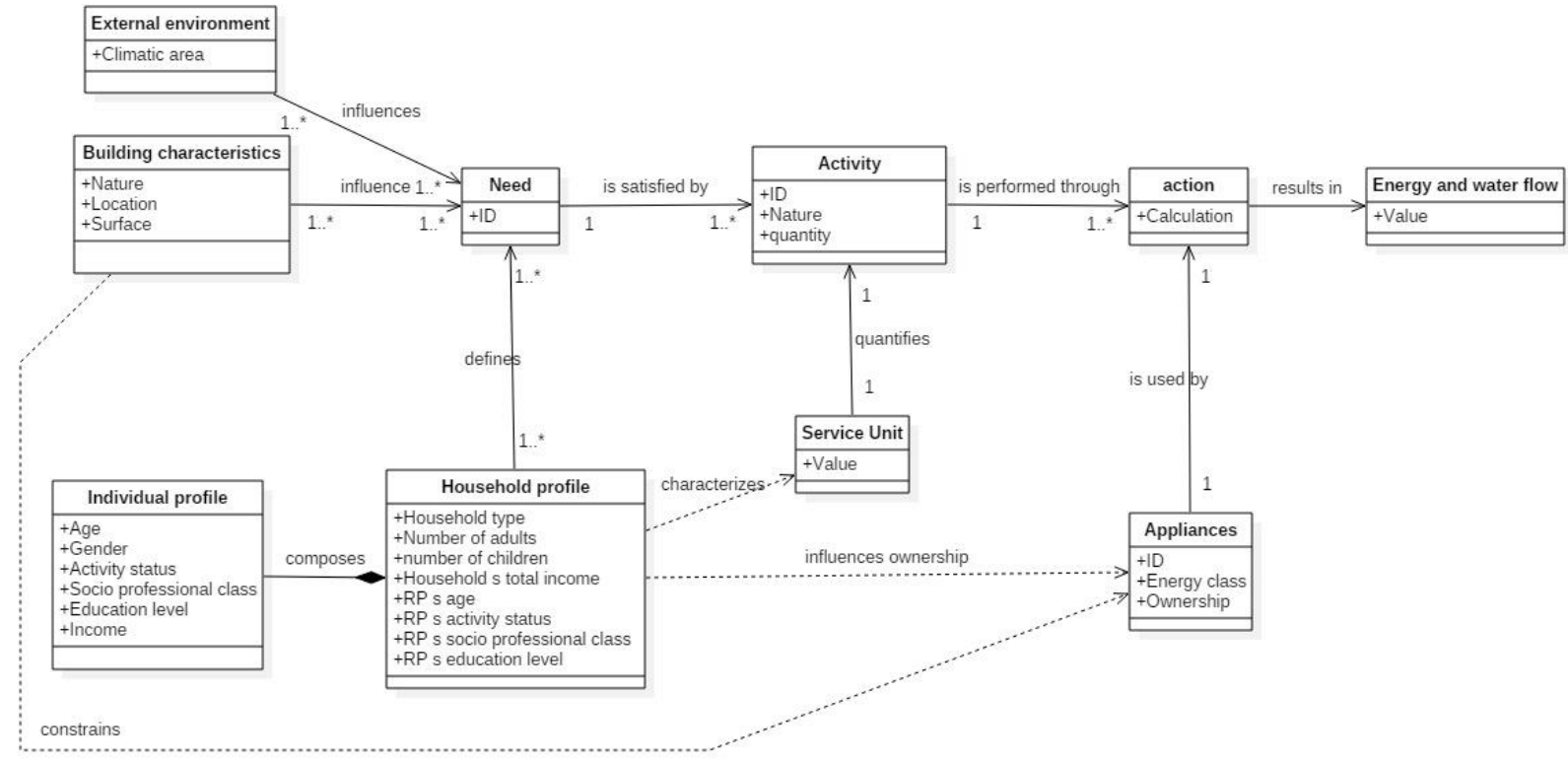

Figure 2: UML class diagram of the Stochastic Activity-Based Energy Consumption model

This triplet need-activity-action characterizes a continuous interaction between occupants and their built environment. We first define the "need" as the true driver of human behaviour. Needs may be physiological or psychological and are satisfied through activities. Seven types of energy-use-related needs are identified in accordance with Maslow's pyramid, such as house-caring and self-feeding (Table 1). An 'activity' is defined as a functional element performed by an individual or group of individuals in order to satisfy their daily living needs and well-being. For example, 'washing laundry' and 'preparing food' are two different activities (Table 1). An 'action' is the way of caring out an activity (response to how an activity is carried out). The action is a set of domestic intentional acts leading directly (by using a home appliance) or indirectly to energy consumption. For instance, two actions may be attributed to the activity 'washing laundry': (1) by hands, or (2) using a washing machine. Therefore, activities and actions represent the means by which occupants interact with their living habitat (appliances, building, and external environment).

\subsection{Characterizing households and individuals}

The way a household performs activities is influenced directly by the habits and lifestyle of its individuals as well as their personal preferences (for example: use of appliances, lighting levels, indoor temperature preferences, etc.) [29]. In this perspective, households' variables such as size, composition, revenue, and life stage must be taken into account [52]. The attributes describing individuals and households, which are considered in the model, are chosen based on literature review and statistical studies. A household $(H H)$ comprises one or more individuals living in the same dwelling and who can interact with each other and with the building and its systems. Each individual is characterized by a number of attributes (such as age and income), while the characteristics of a household are represented mainly by those of its reference person (RP) (Table 2). The definition of reference person (or household head) is widely adopted in scientific literature [31,36,53] and French national statistics [54]). The reference person is defined as the elder economically-active individual among household adults. The reference person is considered as the representative of a household's socio-economic status. The list of attributes characterizing households and individuals is given in Table 2. To our knowledge, it is the first time that a so complete list of household characteristics is integrated into a forecasting model of energy and water consumptions of residential buildings.

Table 2: Households' and individuals' attributes [54] 


\begin{tabular}{ll}
\hline Individual attributes & Household attributes \\
\hline Age & Household type \\
Gender & Number of adults \\
Activity status & Number of children \\
Socio-professional class & Household's total income \\
Education level & RP's age \\
Income & RP's activity status \\
& RP's socio-professional class \\
& RP's education level \\
\hline
\end{tabular}

The number of occupants is a major determinant of energy consumption in dwellings. Households with higher number of occupants logically show higher occupancy patterns and perform more energy-consuming activities, thus leading to higher energy consumption levels. The household type represents the structure of a family. The French population is classified into the five household types as shown in Table 3.

Table 3: Household types [55]

\begin{tabular}{ll}
\hline Household type & Percentage share in the total population \\
\hline Singles & 33,5 \\
Couples without children & 26,1 \\
Couples with at least one & 27,4 \\
child & 7,9 \\
One-parent households & 5,1 \\
Composite households & 100 \\
Total & \\
\hline
\end{tabular}

The age of an individual can exert a strong influence on energy consumption. Individuals perform different activities, purchase different equipments and have different comfort preferences according to their age. The French population is classified into different age segments as shown in Table 4.

Table 4: Age categories of the French population [55]

\begin{tabular}{ll}
\hline Age & Percentage share in the total population \\
\hline Less than 26 & 30,5 \\
$26-35$ & 12,3 \\
$36-45$ & 13,3 \\
$46-55$ & 13,6 \\
$56-65$ & 12,7 \\
$66-75$ & 8,6 \\
$>75$ & 9,1 \\
Total & 100 \\
\hline
\end{tabular}

The Activity/Employment status influences directly the occupancy profiles of household's individuals, inducing thus a high impact on energy consumption trends. For instance, un-employed individuals and retired people are logically more present at home than working individuals, performing thus more domestic activities and consuming more energy. The activity/employment status is considered in the framework through five discrete values as shown in. 
Table 5: Activity and employment status categories [55]

\begin{tabular}{ll}
\hline Activity/employment status & Percentage share in the total population \\
\hline Active-employed & 51,3 \\
Active-unemployed & 5,2 \\
Inactive (15 to 24 years) & 9.1 \\
Inactive (>65 years) & 19,9 \\
Other inactive & 14,5 \\
Total & $100 \%$ \\
\hline
\end{tabular}

Energy consumption is highly correlated to the social and professional class of households [30,35]. For instance, occupancy hours at home depend on individuals' working hours and so do domestic activity patterns. The socio-professional classes of the French population considered in the framework are summarized in Table 6.

Table 6: Socio-professional categories [55]

\begin{tabular}{ll}
\hline Socio-professional category & Percentage share in the total population \\
\hline Independent & 8,6 \\
Senior managerial staff & 15,6 \\
Middle level professions & 23,1 \\
Clerical and service staff & 29,2 \\
Manual workers & 23,5 \\
Total & $100 \%$ \\
\hline
\end{tabular}

As for the education level variable, the French population is clustered into seven categories as in Table 7.

Table 7: Education level categories [55]

\begin{tabular}{ll}
\hline Education level & Percentage share in the total population \\
\hline No diploma or CEP & 26,2 \\
Junior high school certificate & 6,8 \\
CAP (vocational training certificate), & 20,3 \\
BEP & 14,2 \\
Baccalaureat, or equivalent & 9,4 \\
Short-term higher education & 12,5 \\
Long-term higher education & 10,6 \\
Pursuing initial studies & $100 \%$ \\
Total & \\
\hline
\end{tabular}

The income has an impact on equipment ownership and energy consumption levels. Some studies show that the higher income of a household, the higher the number of domestic appliances owned is [56]. Moreover, it may be hypothesized that households with higher incomes afford to consume more energy than those with lower incomes who are restrained by their budget, and thus tend to reduce their consumption. Income classification for the French population is given in Table 8. 
Table 8: Income categories per French individual [55]

\begin{tabular}{ll}
\hline Monthly net income (Euros) & Percentage share in the total population \\
\hline Less than 700 & 7,6 \\
$700-1000$ & 11,6 \\
$1000-1500$ & 20,8 \\
$1500-2000$ & 17,4 \\
$2000-3000$ & 24,9 \\
$3000-4500$ & 13,1 \\
More than 4500 & 4,6 \\
Total & 100 \\
\hline
\end{tabular}

In addition to the preceding fundamental variables, an important intermediary variable is introduced, namely the 'environmental awareness'. The latter represents individuals' attitudes towards purchasing energy efficient appliances as well as their energy consumption patterns. People with higher environmental awareness levels are more conscious to sustainable development and more respectful to energy reduction policies. They possess mainly energy efficient appliances and they often try to limit energy squandering. Environmental awareness can affect appliance ownership levels as well as energy consumption behaviour of occupants. For instance, an energy-conscious individual would rather prefer to buy low-energy consuming appliances, and will apply certain energy-efficient habits such as turning off light when not necessary. Literature review and statistical studies have shown that the environmental awareness of an individual can be estimated as a function of three attributes: income, age, and education level [31,57]. The classification of environmental awareness levels is adopted from a French study which distribute environmental awareness into different levels ranging from 1 to 5 [57]. High environmental awareness (HEA) corresponds to levels 4 and 5, while low environmental awareness to levels 1, 2 and 3 (Table 9). According to Maresca et al. [57], the environmental awareness level of a given household is mainly influenced by three determinants: household's total income, reference person's age, and reference person's education level.

Table 9: : Environmental awareness levels (from Maresca et al. [57])

\begin{tabular}{ll}
\hline Level & Environmental awareness \\
\hline 1 & Very little aware \\
2 & Little aware \\
3 & Moderately aware \\
4 & Enough aware \\
5 & Very aware \\
\hline
\end{tabular}

\subsection{Mapping household attributes to appliance ownership and characteristics}

The second part of the framework consists of establishing probabilistic relations between households' attributes on the one hand, and the ownership of home appliances as well as their characteristics on the other hand. In literature, simple probabilities (conditional probability of one variable given another one) are adopted, however in our case, joint conditional probabilities (conditional probability of one variable given three others) are used in order to have more robust calculations. The formula used for calculating the joint conditional probability $P\left(A \mid D_{i}\right)$ of an event A given three (or more) dependant events $D_{i}(\mathrm{i}=1, \ldots, \mathrm{n})$ is adopted from [58] and presented in equation 1.1. 
$P\left(A \mid D_{i}, i=1, \ldots, n\right)=\frac{1}{1+x} \in[0,1]$

With $x=\frac{\prod_{n=1}^{n} d_{i}}{a^{n-1}} \geq 0$

and $a=\frac{1-P(A)}{P(A)} ; d_{i}=\frac{1-P\left(A \mid D_{i}\right)}{P\left(A \mid D_{i}\right)}, i=1, \ldots, n$

First, the ownership rate of an appliance is estimated through a conditional probability as a function of three variables: household's type, reference person's age, and reference person's socio-professional class. The marginal probability distributions are taken from a national French statistics [59]. An example of such probability distributions is given in table 10. Second, the energy-efficiency of an appliance is estimated through another joint conditional probability as a function of households' revenue, reference person's age, and households' environmental awareness level. The marginal probability distributions are taken from another national study [57].

Table 10: Appliance ownership rate (\%) as a function of household type

\begin{tabular}{llllll}
\hline Appliances & \multicolumn{5}{c}{ Appliances ownership probability as a function of household type } \\
\hline & Single & $\begin{array}{l}\text { One- } \\
\text { parent } \\
\text { family }\end{array}$ & $\begin{array}{l}\text { Couples } \\
\text { without } \\
\text { children }\end{array}$ & $\begin{array}{l}\text { Couple with one } \\
\text { children or more }\end{array}$ & $\begin{array}{l}\text { Other } \\
\text { households }\end{array}$ \\
\cline { 2 - 6 } Refrigerator & 99,4 & 100 & 100 & 100 & 100 \\
Freezer & 76,3 & 88,9 & 92,8 & 94,7 & 88,7 \\
Micro-wave oven & 76,1 & 90,5 & 86,1 & 93,7 & 87,6 \\
Cloth washer & 87,5 & 98,8 & 98,5 & 99,6 & 93,5 \\
Dishwasher & 27,2 & 46,6 & 63,8 & 72,1 & 42 \\
Color TV & 95,3 & 98,6 & 98,8 & 98,7 & 97,8 \\
VCD, DVD player & 69,7 & 88,4 & 87,6 & 95,4 & 83,8 \\
Landline phone & 83,2 & 82,6 & 94,3 & 93,3 & 89,4 \\
Mobile phone & 64 & 90,4 & 82,6 & 95,7 & 81 \\
Computer & 45,8 & 77,7 & 63,1 & 92,9 & 68,8 \\
Internet & 39 & 69,1 & 57,7 & 87,6 & 60,1 \\
\hline
\end{tabular}

\subsection{Quantifying an activity}

The estimation of activity quantities per household and per individual as a function of their attributes is the major novel contribution of this work. In order to quantify a given activity, we define a quantification unit namely the 'service unit'. This definition is based on the definition of the functional unit in Life Cycle Assessment (ISO 14044). For example, we define the service unit of the activity 'washing dishes' to be the total quantity of used dishes and cutlery per month, and that of the activity 'washing clothes' as the quantity of clothes to be washed per month. As pointed out earlier through model's architecture (Figure 2), the quantity of an activity is disaggregated to both household's and individuals' levels as a function of attributes. The service unit of an activity is determined basically per individual. Then, the service unit per household is determined by aggregating the service units of all household members (Figure 3). This aggregation depends on the nature of the activity, whether it is a shared or an additive one. For the sharing case, data can be obtained either from nation-wide surveys or determined through meaningful heuristic logics which are further fitted to global national data of consumption. Moreover, the authors are collaborating with an industrial construction partner who is providing real monitored energy use of occupants. This monitoring data is therefore being used to validate modelling hypothesis, as well as to validate simulation results. 


\subsubsection{Activity nature}

The nature of a domestic activity determines the quantification mechanism of its service unit. We distinguish here two types of activities: additive and shared (Table 1). An activity is said to be shared if its service unit can be shared by two or more household members. For instance, 'watching TV' is considered as a shared activity since, in most cases, family members watch TV together. Thus the total service unit of this activity at the household level is not the sum of all individual activities, but it is rather an aggregated sum with a percentage of sharing. Shared activities may also be carried out individually. On the other side, an activity is said to be additive if sharing does not take place. In this case, the service unit at the household level is equal to the sum of all individual service units. For instance, using computers, bathing and washing laundry are additive activities. It must be noted here that we consider the sharing and non-sharing as a function of the activity's service unit, and not as a function of the appliance. In other words, people may share the same appliance for the same activity; however they do not share the service unit. A direct example of this is the 'washing laundry' activity. The service unit of this activity is defined as the 'quantity of laundry' generated per household per month. In general, household members use the same washing machine at home, yet their service units are rather additive and not shared. This is because each individual uses his/her own laundry differently than others (different quantities, different changing frequency, etc.), where the total service unit for the household is the summation all the individual service units.

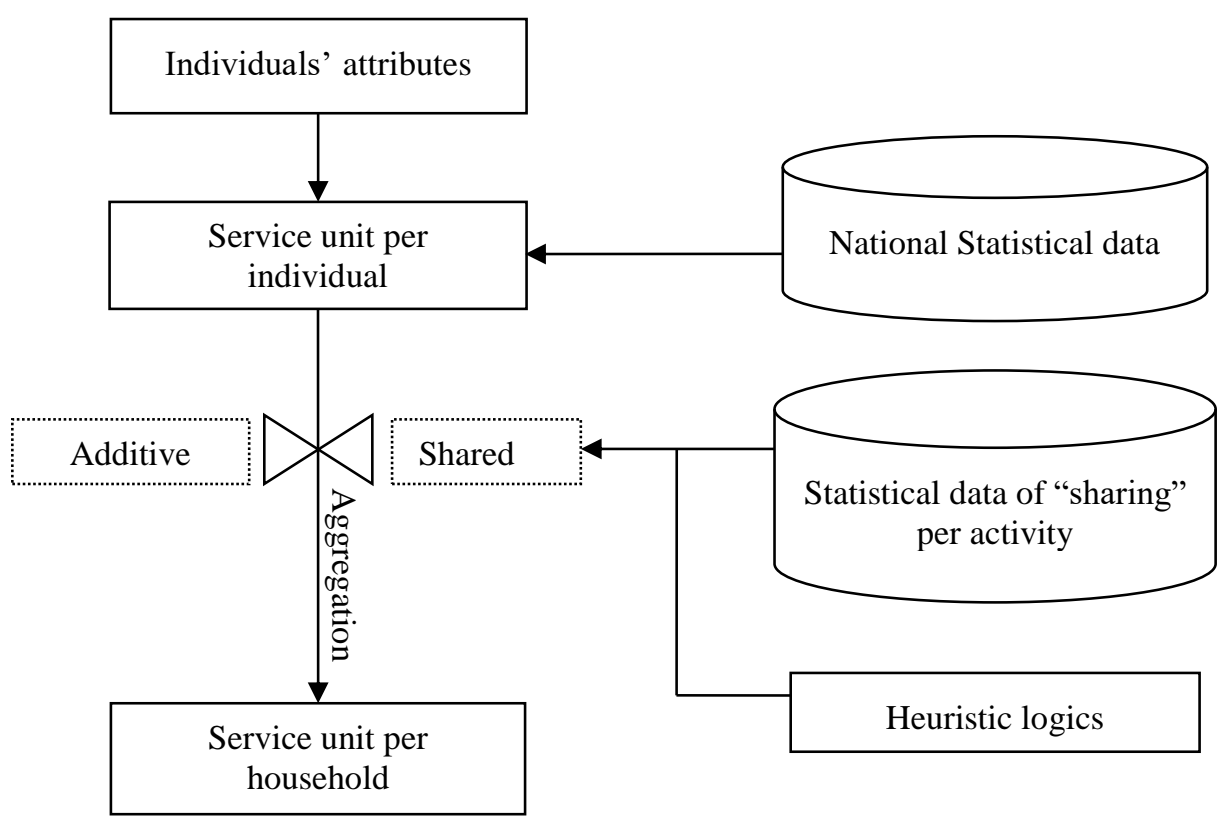

Figure 3: Determining the service unit of an activity

\subsubsection{Cascading of service units between activities}

For the sake of convenience, different activity service units (SUs) may be expressed from a same or shared intermediary SU variable. For instance:

- The number of breakfasts and lunch/dinner meals are two intermediary SU variables that allow calculating water and electricity consumptions used for the two activities: 'washing dishes' and 'cooking', 
- The weight of dirty clothes per week is an intermediary SU variable that can be used for calculating energy and water consumptions for the three different activities: 'washing clothes', 'drying clothes', and 'ironing clothes'.

In order to represent all these interdependencies among activities, a complete dependency framework of intermediate and final service units has been established. A detailed description is beyond the objective of this paper, yet a guiding example is given hereafter for the three laundry-related activities.

\section{Application example of the cascading/service unit network on the laundry activity}

We provide here a limited view of our SU (service unit) network. An example is taken on the aggregate laundry activity as illustrated in Figure 4: if a household washes a quantity of laundry (washing machine), a proportional quantity is thus expected to be dried (tumble dryer) and a part of this quantity to be ironed at home (iron). The service unit of the inheriting activity will thus be a function of its predecessors'. For instance, the service unit of the activity 'ironing laundry' can be plugged onto the activity 'washing laundry', without being obliged to start from zero. Some additional influencing parameters such as the percentage of laundry to be ironed over the total laundry quantity may also be considered.

\subsection{Determining energy and water consumption for an activity}

Given the probabilistic nature of the variables, Monte-Carlo technique is used to run simulations. At each simulation run, all random variables are re-initialized to determine deterministic values which are then used in the calculation. The number of simulation runs is determined according to the convergence of the results. During each simulation run, random variables are generated to calculate: (1) the ownership of appliances, (2) the environmental awareness level of the household, (3) the energy-efficiency of appliances, and (4) the appliance technology. The energy consumed by an activity for a given household, is thus calculated stochastically as a function of the service unit (which is the quantity of activity per duration unit) and the characteristics of the appliance (power rating, size, and technology) involved in the activity (sections 4.3 and 4.4). 


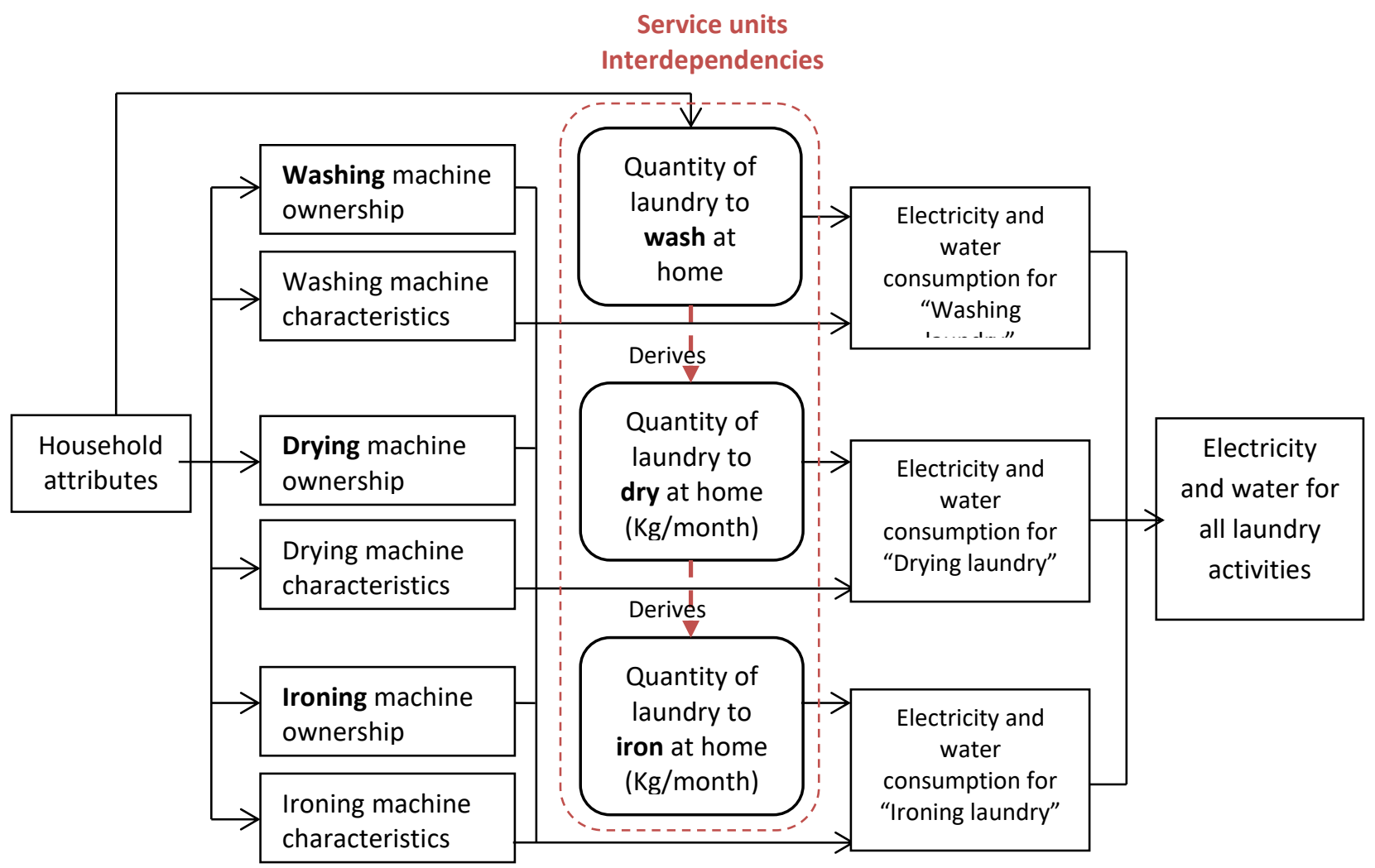

Figure 4: Service unit interdependencies for the three activities concerning laundry at home

One should notice that the model is of stochastic nature due to the probabilistic mapping established between household attributes on the one hand (taken as inputs) and the corresponding appliance ownership, appliance characteristics and power rating, and activity quantities on the other. Given this probabilistic nature, MonteCarlo technique is used to conduct simulations. Moreover, the model is capable of generating random households automatically (i), rather than being specified by the user as input. In addition, constraints may be defined on some (or all) household's attributes in order to conduct specific consumption-variability analysis (ii).

\section{Application example of the framework for the activity "watching TV"}

\subsection{Activity-based framework for the "watching TV' activity}

In this section, a demonstration of the proposed activity-based framework is performed on the 'Watching TV' activity. A modelling framework for the subject activity is first established as shown through Figure 5. 


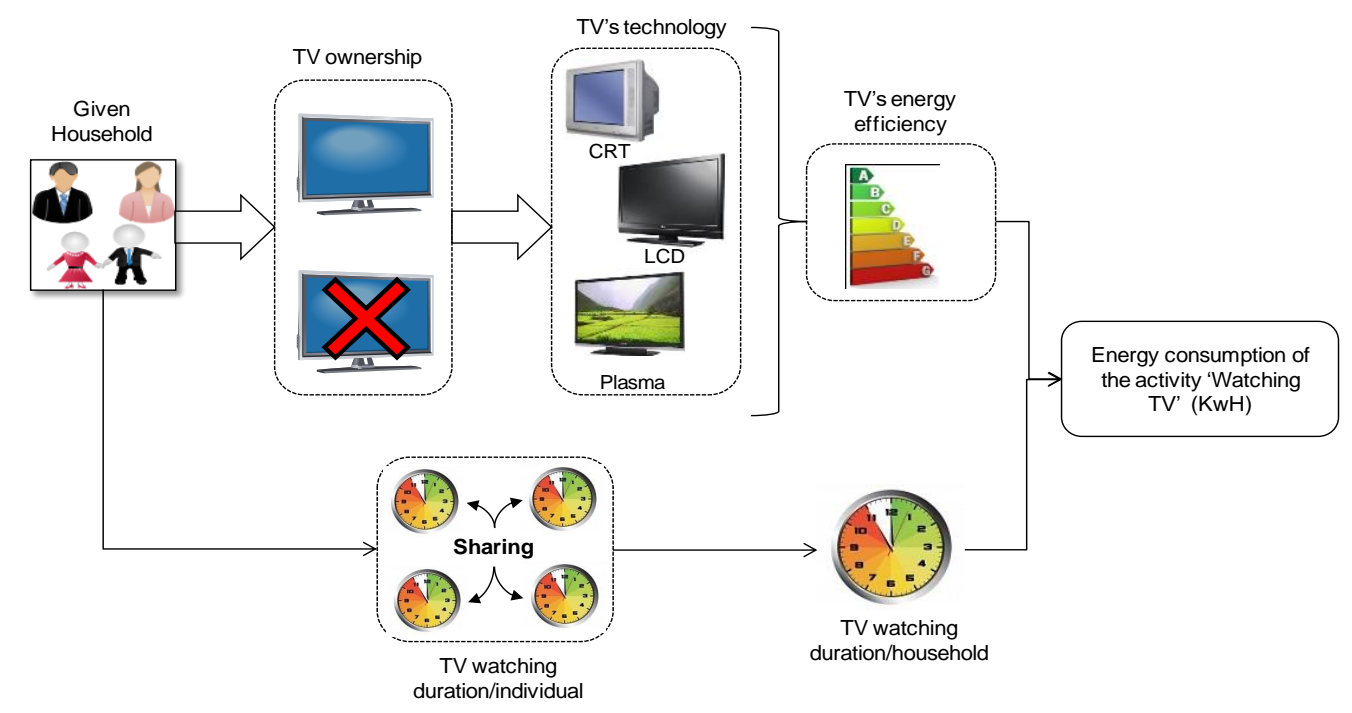

Figure 5: Applying the modelling framework for the activity "watching TV"

The procedure for estimating the energy consumption used by a given household for performing the activity 'watching TV', is described through the following four steps:

First step: Determining the ownership rate (probability) of the television appliance. A probabilistic relation is established to estimate the ownership rate as a function of a household's type, reference person's age, and reference person's socio-professional category. National statistical data are used for this aim.

Second step: Determining the technology and power rating of the TV appliance. Televisions can exist in multiple technologies and energy ratings. National statistical distributions are used to attribute stochastically a given technology for the TV appliance owned by the household. Once the technology of the TV is determined, its corresponding power rating interval can be deduced from technical documents. During simulation, a power rating value is chosen arbitrarily from this interval.

Third step: Quantifying the service unit of the activity 'watching TV'. The service unit for this activity is defined to be the watching duration in minutes per day per household. First, service units for all household individuals are taken from national statistical surveys giving watching duration of TV per individual per day as a function of his/her age and socio-professional class [54]. Knowing that household members can watch TV simultaneously, a sharing coefficient of common watching durations must be taken into account. For the French population, a national survey gives sharing coefficients for the 'watching TV' activity as a function of household's type as shown in Table 11 [54].

Table 11: Sharing coefficient for the 'watching TV' activity as a function of household type

\begin{tabular}{ll}
\hline Household type & Sharing coefficient per individual \\
\hline Single person & 0 \\
One-parent family & 0,51 \\
Couples without children & 0,74 \\
Couples with children & 0,71 \\
Others & 0,57 \\
\hline
\end{tabular}


Fourth step: Calculating activity's energy consumption (for active and standby modes). Using the service unit together with the power rating of the appliance, the energy consumption yielded by the 'watching TV' activity can thus be estimated. Given the stochastic nature of the model, each simulation run will result in a different combination of variables, and thereby in different consumption values. The number of simulation iterations is adjusted according to the convergence of the results. Finally, the resulting consumption values are represented through a statistical distribution giving thus a 'spectrum' of electricity consumption yielded by the subject activity.

In what follows, some simulation examples of electricity consumption for the 'watching TV' activity are presented. The simulations are conducted according to the aforementioned procedure presented earlier. Figure 6 shows electricity consumption distributions for five different (manually defined) households (HH). The box plots in this figure reveal how the consumption values can vary from household to another, where each box plot corresponds to a thousand simulations. For instance, the first household (HH1), which corresponds to a 'single-person' type, shows a median electricity consumption value of $2.5 \mathrm{KWh} / \mathrm{week}$. On the other hand, the third household (HH3), which corresponds to a 'couple with children' family, shows a median consumption of $5 \mathrm{KWh} /$ week.

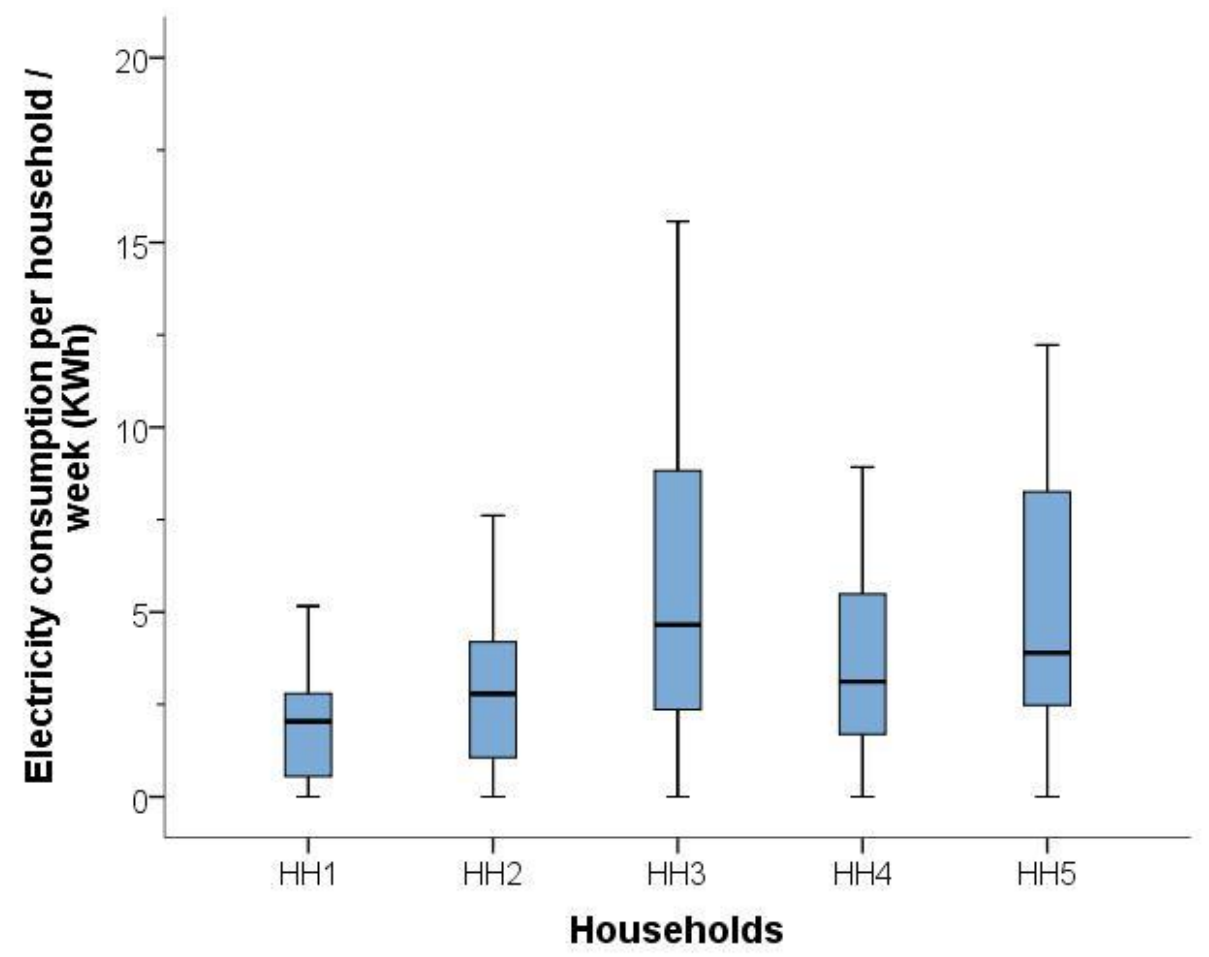

Figure 6: Simulated electricity consumption for the activity 'watching TV': Comparison of five different households

Another example of simulation results for the activity 'watching TV' is given in Figure 7. In this example, a constraint is defined on the household type: only 'couples with children' families are considered. The simulation is conducted to assess variability in consumption values as a function of the number of children present in each household. It can be noticed from this figure how electricity consumption increases with the increase in the number of children. 


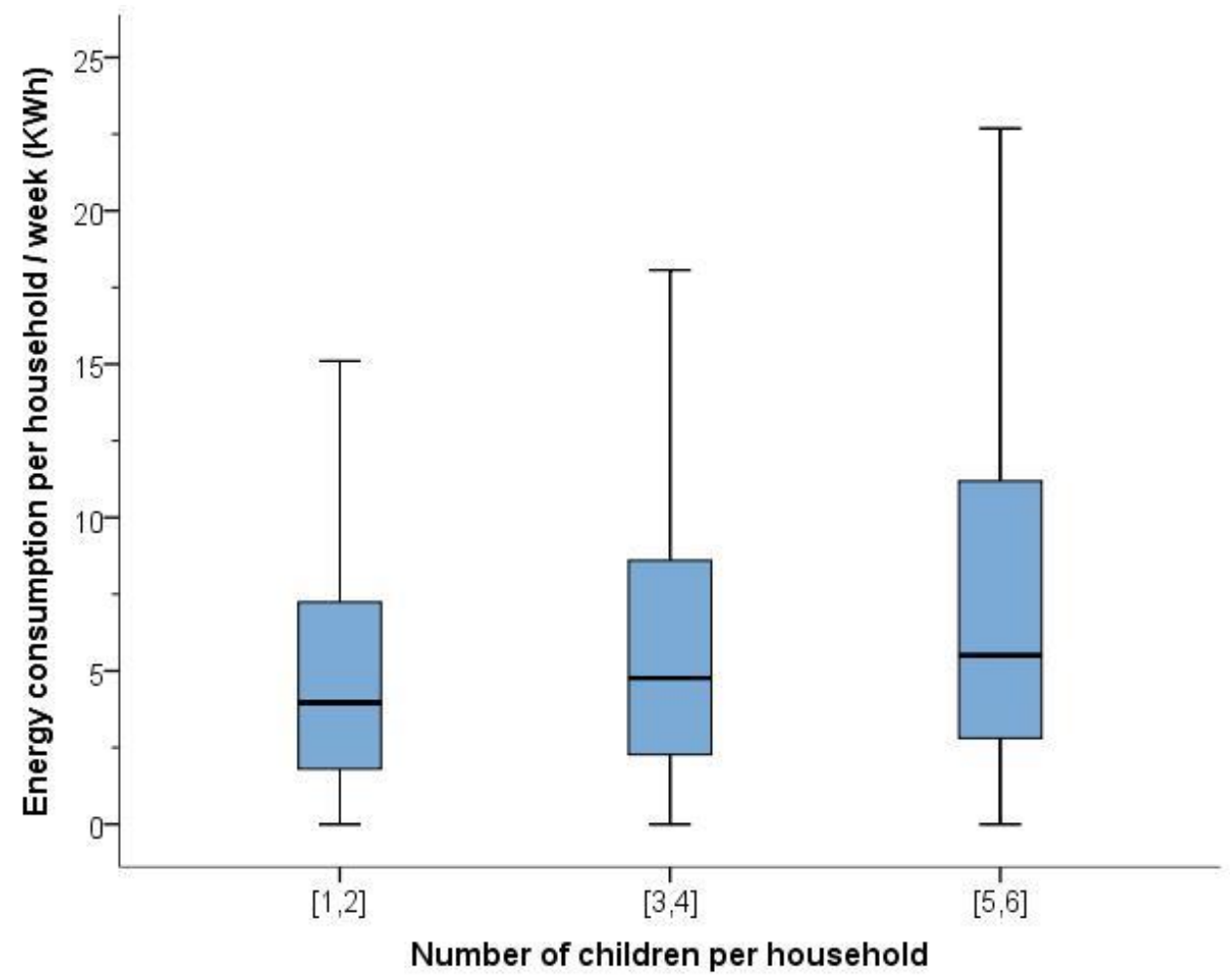

Figure 7: Simulated electricity consumption for the activity 'watching TV': Comparison of households with different number of children

\subsection{Simulation model validation}

To validate the model of the 'watching TV' activity, real measured data are taken from a national French study [60]. This study measures electricity consumption of television devices in 99 French households, where the households are chosen arbitrary without any constraints on their demographic and socioeconomic attributes. For validating the framework, consumption values are thus taken from the above mentioned study, and compared to samples of simulation results. This comparison is illustrated through Figure 8 for which 10000 simulation runs were performed. The similarity between both distributions is assessed through a Mann-Whitney Wilcoxon test., a non-parametric test that validates that a distribution is the same between two different groups, especially for independent and non-normal distributions. We run the test with a 95\% confidence interval. The $p$-value resulting from the test is equal to 0.427 . For Mann-Whitney-Wilcoxon test, this p-value indicates that the null hypothesis can be retained, meaning that both samples have the same distribution Results confirm the similarity of energy consumption distributions for activity 'watching TV' between simulation results and real data. These results give a clear validation of SABEC simulation model for "watching TV" activity. This first validation test succeeds to validate our simulation model. An additional campaign of measurements of households' energy consumption is under progress. Results from this campaign will participate to go further into the validation step. 


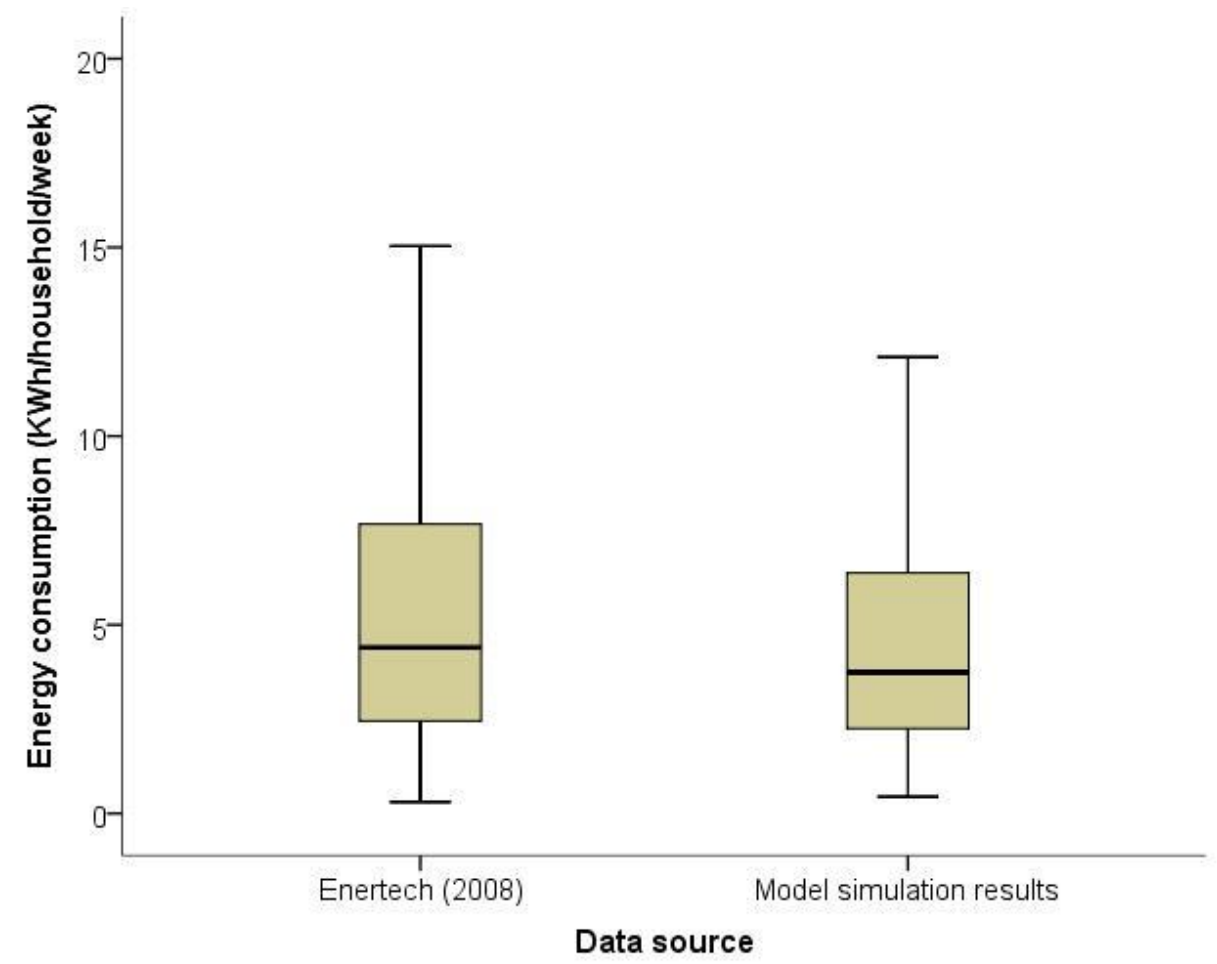

Figure 8: Comparison of electricity consumption for the activity 'watching TV': Simulation results against real-data (99 households)

\section{Discussions, conclusions and perspectives}

In this paper, a bottom-up activity-based approach for forecasting residential energy consumption is proposed. First, a systematic breakdown structure of energy use is established. A detailed list of domestic energy-consuming activities is then proposed, where these activities are classified according to their nature (shared or additive). The activity-based modelling framework is then presented in details. In order to quantify a given activity, the notion of 'activity's service unit' is introduced. Service units are measures of activity quantities per duration unit, and are consequently linked to energy and water demand at both individual and household levels. Activity's service units can then be associated to the usage of one or more domestic appliances in order to predict energy consumption. The proposed activity-based approach can account for dependencies between service units of different activities. This is an important feature for modelling the total energy consumption yielded by all domestic activities as a whole. To account for the variability of household profiles, a fairly sufficient number of household an occupant driven attributes is considered.

The modelling framework was then demonstrated through an example application for the 'watching TV' activity. The modelling steps are illustrated and a sample of simulation results is presented. These results for this activity are then validated against real-measured data coming from a national French study. The illustration of the framework through this example activity reveals the interest of our approach for building appropriate parametric and probabilistic consumption models from household profile attributes. The authors are collaborating with an industrial construction partner who is providing real monitored energy use of occupants. This monitoring data is therefore being used to validate modelling hypothesis, as well as to validate simulation results. 
As shown through simulation results, the model may be used to produce precise energy consumption intervals, per activity and per household. Moreover, the framework allows assessing energy consumption variability between different household profiles. Given these features, such a model may thus be coupled to industrial energy simulators to produce more accurate energy estimations with a reduced uncertainty [49]. This is a substantial point for addressing the growing market of 'energy performance contracts'. Finally, the originality of our work is the decomposition of electro-domestic consumption by activities. This is of the utmost importance since occupants can and know how to regulate their activities. This model could be central to the development of a connected building approach, to the Internet of Things at the service of information and regulation of consumption. Although to date, we still do not have adequate technical resources for allocating consumption by activities, we can get ahead by calculating consumption by reference activities from the cloud data "for comparable family", develop visualization interfaces and offer occupants means to voluntarily de-consume (incentives, emulation by social network, diagnostic and support to action plan ...).

\section{References}

[1] R. Saidur, H.H. Masjuki, M.Y. Jamaluddin, An application of energy and exergy analysis in residential sector of Malaysia, Energy Policy. 35 (2007) 1050-1063. doi:10.1016/j.enpol.2006.02.006.

[2] O.T. Masoso, L.J. Grobler, The dark side of occupants' behaviour on building energy use, Energy Build. 42 (2010) 173-177. doi:10.1016/j.enbuild.2009.08.009.

[3] F. Meijer, L. Itard, M. Sunikka-Blank, Comparing European residential building stocks: performance, renovation and policy opportunities, Build. Res. Inf. 37 (2009) 533-551. doi:10.1080/09613210903189376.

[4] L. Yang, H. Yan, J.C. Lam, Thermal comfort and building energy consumption implications - A review, Appl. Energy. 115 (2014) 164-173. doi:10.1016/j.apenergy.2013.10.062.

[5] EPBD, Concerted Action | Energy Performance of Buildings Directive, (2014).

[6] S. Vierra, Green Building Standards and Certification Systems | Whole Building Design Guide, (2011).

[7] CPE, Contrats de performance énergétique - Ministère du Développement durable, (2012).

[8] Z. Yu, B.C.M. Fung, F. Haghighat, H. Yoshino, E. Morofsky, A systematic procedure to study the influence of occupant behavior on building energy consumption, Energy Build. 43 (2011) 14091417. doi:10.1016/j.enbuild.2011.02.002.

[9] S. Pachauri, An analysis of cross-sectional variations in total household energy requirements in India using micro survey data, Energy Policy. 32 (2004) 1723-1735. doi:10.1016/S03014215(03)00162-9.

[10] V. Fabi, R. Andersen, S. Corgnati, B. Olesen, Occupants' window opening behaviour: A literature review of factors influencing occupant behaviour and models, Build. Environ. 58 (2012) 188-198.

C. Malavazos, D. Tzovaras, D. Kehagias,, D. Ioannidis, Energy and behavioural modelling and 
simulation for ee-buildings design, in: Proc. CIB W78-W102 2011 Int. Conf., Sophia Antipolis, France, 2011.

[12] M. Fischer, J. Kunz, The scope and role of information technology in construction, in: ProceedingsJapan Soc. Civ. Eng., 2004: pp. 1-32.

[13] A. Kashif, S. Ploix, J. Dugdale, X.H. Binh Le, Simulating the dynamics of occupant behaviour for power management in residential buildings, Energy Build. (2012). doi:10.1016/j.enbuild.2012.09.042.

[14] P. Hoes, J. Hensen, M. Loomans, B. De Vries, D. Bourgeois, User behavior in whole building simulation, Energy Build. 41 (2009) 295-302.

[15] L.G. Swan, V.I. Ugursal, Modeling of end-use energy consumption in the residential sector: A review of modeling techniques, Renew. Sustain. Energy Rev. 13 (2009) 1819-1835. doi:10.1016/j.rser.2008.09.033.

[16] R. Yao, K. Steemers, A method of formulating energy load profile for domestic buildings in the UK, Energy Build. 37 (2005) 663-671.

[17] K. Gram-Hansen, Residential heat comfort practices: understanding users, Build. Res. Inf. 38 (2010) 175-186. doi:10.1080/09613210903541527.

[18] U. Wilke, F. Haldi, J.L. Scartezzini, D. Robinson, A bottom-up stochastic model to predict building occupants' time-dependent activities, Build. Environ. 60 (2013) 254-264. doi:10.1016/j.buildenv.2012.10.021.

[19] D. Robinson, Some trends and research needs in energy and comfort prediction, in: Wind. Conf., 2006.

[20] A.F. Emery, C.J. Kippenhan, A long term study of residential home heating consumption and the effect of occupant behavior on homes in the Pacific Northwest constructed according to improved thermal standards, Energy. 31 (2006) 677-693. doi:10.1016/j.energy.2005.04.006.

[21] O. Guerra-Santin, L. Itard, Occupants' behaviour: determinants and effects on residential heating consumption, Build. Res. Inf. 38 (2010) 318-338. doi:10.1080/09613211003661074.

[22] J. Page, D. Robinson, N. Morel, J.L. Scartezzini, A generalised stochastic model for the simulation of occupant presence, Energy Build. 40 (2008) 83-98.

[23] Clevenger, Haymaker, The impact of the building occupant on energy modeling simulations, in: Jt. Int. Conf. Comput. Decis. Mak. Civ. Build. Eng. Montr. Canada, 2006: pp. 1-10.

[24] J. Seryak, K. Kissock, Occupancy and behavioral affects on residential energy use, in: Proc. Sol. Conf., 2003: pp. 717-722.

[25] W. O'Brien, H.B. Gunay, F. Tahmasebi, A. Mahdavi, A preliminary study of representing the interoccupant diversity in occupant modelling, J. Build. Perform. Simul. 0 (2016) 1-18. doi:10.1080/19401493.2016.1261943. 
[26] T. Zaraket, B. Yannou, Y. Leroy, S. Minel, E. Chapotot, An occupant-based energy consumption model for user-focused design of residential buildings, J. Mech. Des. Trans. ASME. 137 (2015). doi:10.1115/1.4030202.

[27] A. Perrels, C. Weber, Modelling Impacts of Lifestyle on Energy Demand and Related Emissions, Energy Policy. 28 (2000) 1-39.

[28] I. Mansouri, M. Newborough, D. Probert, Energy consumption in UK households: Impact of domestic electrical appliances, Appl. Energy. 54 (1996) 211-285.

[29] L. Picon, B. Yannou, T. Zaraket, S. Minel, G. Bertoluci, F. Cluzel, R. Farel, Use-phase memory: A tool for the sustainable construction and renovation of residential buildings, Autom. Constr. 36 (2013) 53-70. doi:10.1016/j.autcon.2013.08.003.

[30] G.Y. Yun, K. Steemers, Behavioural, physical and socio-economic factors in household cooling energy consumption, Appl. Energy. 88 (2011) 2191-2200. doi:10.1016/j.apenergy.2011.01.010.

[31] S. Barr, A.W. Gilg, N. Ford, The household energy gap: examining the divide between habitualand purchase-related conservation behaviours, Energy Policy. 33 (2005) 1425-1444. doi:10.1016/j.enpol.2003.12.016.

[32] L. Lutzenhiser, S. Bender, The "Average American" Unmasked: Social Structure and Differences in Household Energy Use and Carbon Emissions., in: 2008.

[33] D.A. Guerin, B.L. Yust, J.G. Coopet, Occupant predictors of household energy behavior and consumption change as found in energy studies since 1975, Fam. Consum. Sci. Res. J. (2000) 4880.

[34] S.B. Nugroho, A. Fujiwara, J. Zhang, K. Kanemoto, S.S. Moersidik, S. Abbas, DEVELOPMENT OF A HOUSEHOLD ENERGY CONSUMPTION MODEL FOR MEGACITIES IN ASIA, in: Hong Kong, 2010.

[35] M. Santamouris, K. Kapsis, D. Korres, I. Livada, C. Pavlou, M.N. Assimakopoulos, On the relation between the energy and social characteristics of the residential sector, Energy Build. 39 (2007) 893-905. doi:10.1016/j.enbuild.2006.11.001.

[36] F. McLoughlin, A. Duffy, M. Conlon, Characterising domestic electricity consumption patterns by dwelling and occupant socio-economic variables: An Irish case study, Energy Build. 48 (2012) 240248. doi:10.1016/j.enbuild.2012.01.037.

[37] Y.G. Yohanis, J.D. Mondol, A. Wright, B. Norton, Real-life energy use in the UK: How occupancy and dwelling characteristics affect domestic electricity use, Energy Build. 40 (2008) 1053-1059. doi:10.1016/j.enbuild.2007.09.001.

[38] Y.-S. Chiou, Deriving US household energy consumption profiles from american time use survey data a bootstrap approach, in: 11th Int. Build. Perform. Simul. Assoc. Conf. Exhib. Glas. Scotl., 2009: pp. 151-158.

[39] Y. Shimoda, T. Fujii, T. Morikawa, M. Mizuno, Residential end-use energy simulation at city scale, Build. Environ. 39 (2004) 959-967. doi:10.1016/j.buildenv.2004.01.020. 
[40] J. Tanimoto, A. Hagishima, H. Sagara, A methodology for peak energy requirement considering actual variation of occupants' behavior schedules, Build. Environ. 43 (2008) 610-619.

[41] J. Tanimoto, A. Hagishima, H. Sagara, Validation of probabilistic methodology for generating actual inhabitants' behavior schedules for accurate prediction of maximum energy requirements, Energy Build. 40 (2008) 316-322. doi:10.1016/j.enbuild.2007.02.032.

[42] I. Richardson, M. Thomson, D. Infield, A high-resolution domestic building occupancy model for energy demand simulations A high-resolution domestic building occupancy model for energy demand simula- tions. Energy and, Buildings. 40 (2008) 1560-1566.

www.elsevier.com/locate/enbuild\%0Ahttp://hdl.handle.net/2134/3112\%0Ahttps://dspace.lboro. ac.uk/2134/4757.

[43] I. Richardson, M. Thomson, D. Infield, C. Clifford, Domestic electricity use: A high-resolution energy demand model, Energy Build. 42 (2010) 1878-1887.

[44] Richardson, Murray Thomson, David Infield, Alice Delahunty, Domestic lighting: A high-resolution energy demand model, Energy Build. 41 (2009) 781-789. doi:10.1016/j.enbuild.2009.02.010.

[45] J. Widén, E. Wäckelgård, A high-resolution stochastic model of domestic activity patterns and electricity demand, Appl. Energy. 87 (2010) 1880-1892. doi:10.1016/j.apenergy.2009.11.006.

[46] M. Muratori, A Highly Resolved Modeling Technique to Simulate Residential Power demand, Appl. Energy. 107 (2013) 465-473.

[47] R. Subbiah, An Activity-Based Energy Demand Modeling Framework for Buildings: A Bottom-Up Approach, Virginia Polytechnic Institute and State University, 2013.

[48] J. Quijano, C. Herpson, N. Sabouret, Prédiction de l'activité humaine afin de réduire la consommation électrique de l'habitat, in: 2010: pp. 43-52.

[49] W. O'Brien, I. Gaetani, S. Gilani, S. Carlucci, International survey on current occupant modelling approaches in building performance simulation 1 Introduction, J. Build. Perform. Simul. 1 (2016) 1-19. doi:10.1080/19401493.2016.1243731.

[50] K. Ellegård, J. Palm, Visualizing energy consumption activities as a tool for making everyday life more sustainable, Appl. Energy. 88 (2011) 1920-1926. doi:10.1016/j.apenergy.2010.11.019.

[51] V. Kaptelinin, Activity Theory. In: Soegaard, Mads and Dam, Rikke Friis (eds.). "The Encyclopedia of Human-Computer Interaction, 2nd Ed.". Aarhus, Denmark: The Interaction Design Foundation. Available online at, (2012).

[52] R. Baetens, D. Saelens, Modelling uncertainty in district energy simulations by stochastic residential occupant behaviour, J. Build. Perform. Simul. 1493 (2015) 1-17. doi:10.1080/19401493.2015.1070203.

[53] A. Druckman, T. Jackson, Household energy consumption in the UK: A highly geographically and socio-economically disaggregated model, Energy Policy. 36 (2008) 3177-3192. doi:10.1016/j.enpol.2008.03.021. 
[54] INSEE, Conditions de vie-Société - Enquête Emploi du temps 2009-2010, (2012).

[55] INSEE, French National Institute of Statistics and Economic Studies, (2015).

[56] D. Young, Who pays for the 'beer fridge'? Evidence from Canada, Energy Policy. 36 (2008) 553560. doi:10.1016/j.enpol.2007.09.034.

[57] B. Maresca, R. Picard, A. Dujin, La consommation d'énergie dans l'habitat entre recherche de confort et impératif écologique, Centre de recherche pour l'étude et l'observation des conditions de vie, 2009.

[58] A.G. Journel, Combining knowledge from diverse sources: An alternative to traditional data independence hypotheses, Math. Geol. 34 (2002) 573-596.

[59] INSEE, Equipement des ménages en biens durables selon le type de ménage, (2010).

[60] ENERTECH, Residential Monitoring to Decrease Energy Use and Carbon Emissions in Europe, (2008). 